\title{
Inovasi Pelayanan Publik Pada Dinas Penanaman Modal Dan Pelayanan Terpadu Satu Pintu (DPMPTSP) Provinsi Riau
}

\author{
${ }^{1}$ Wasiah Sufi, ${ }^{2}$ Prihati , \\ ${ }^{12}$ Fakultas Ilmu Administrasi \\ e-mail : wasiah.sufi@unilak.ac.id
}

\begin{abstract}
Abstrak
Penelitian ini bertujuan mengetahui pelaksanaan inovasi pada DPMPTSP Provinsi Riau dalam memperoleh penghargaan pelayanan publik terbaik se-nasional dan mengetahui faktor pendukung inovasi pada DPMPTSP Provinsi Riau.Pemilihan lokasi penelitian ini berdasarkan fenomena atau masalah yang positif bahwa DPMPTSP Provinsi Riau memperoleh penghargaan pelayanan publik terbaik se-nasioanal dari Kementerian Pendayagunaan Aparatur Sipil Negara dan Reformasi Birokrasi pada Tahun 2018.Teknik pengumpulan data yang di gunakan melalui observasi, wawancara dan dokumentasi.Adapun informan penelitian ini: Kepala DPMPTSP Provinsi Riau, Kepala Bidang DPMPTSP Provinsi Riau, Pegawai DPMPTSP Provinsi Riau, dan Masyarakat.Langkah-langkah analisis data pada penelitian kualitatif menurut Miles and Huberman dalam (Sugiyono 2012:337) adalah reduksi data, penyajiandata dan verifikasi data.Muttaqin dalam (Deddy Mulyadi:2018) bahwa birokrasi yanng dapat melakukan inovasi dalam pelayanan publik, apabila beberapa faktor tersebut berinteraksi satu dengan yang lain dan terintegrasi dalam meciptakan birokrasi pemerintahan yang inovatif. Faktor-faktor tersebut berada pada tataran individu aparatur birokrasi pemerintahan, kelembagaan, sistem, dan masyarakat.
\end{abstract}

\section{Kata Kunci :: Inovasi, Pelayanan Publik}

\begin{abstract}
This reaseach aims to determine the implementation of innovation in Riau Province DPMPTSP in obtaining the best national public service award and to find out the supporting factors for innovation in Riau Province DPMPTSP. The selection of this research location is based on a positive phenomenon or problem that the Riau Province DPMPTSP received the best national public service award from the Ministry of Civil Service Empowerment and Bureaucratic Reform in 2018. Data collection techniques were used through observation, interviews and documentation. The informants of this study: Head of DPMPTSP Riau Province, Head of DPMPTSP Riau Province, Riau Province DPMPTSP Employees, and the Community. The data analysis steps in qualitative research according to Miles and Huberman in (Sugiyono 2012: 337) are data reduction, data presentation and data verification. Muttaqin in (Deddy Mulyadi: 2018) that the bureaucracy can make innovations in public services, if some of these factors interact with one another and are integrated in creating innovative government bureaucracies. These factors are at the individual level of the government bureaucracy, institutions, systems and society.
\end{abstract}

Keyword: Innovation, Public Service

\section{PENDAHULUAN}

Dinas Penanaman Modal dan Pelayanan Terpadu Satu Pintu (DPMPTSP) Provinsi Riau merupakan merupakan unsur penunjang tugas tertentu Pemerintah Provinsi Riau, yang dipimpin oleh seorang Kepala Dinas berada dibawah dan bertanggungjawab kepada Gubernur melalui Sekretaris Daerah. DPMPTSP berwenang dalam penyelenggaraan pelayanan perizinan dan non perizinan satu pintu.Pelayanan perizinan ini pemberian dokumen sebagai bukti legalitas kepada pelaku usaha/kegiatan tertentu.Sedangkan pelayanan non perizinan ini pemberian dokumen atau bukti 
legalitas atas sahnya suatu kepada seseorang atau sekelompok terkait dengan kemudahan pelayanan dalam bentuk fasilitas fiskal dan informasi.

Sistem pelayanan perizinan dan non perizinan menggunakan sistem pelayanan manual dan online. Bagi masyarakat yang sudah bisa menggunakan teknologi informasi pelayanannya bisa secara online dan ada juga masyarakat dengan cara manual datang ke kantornya lansung. Untuk meningkatkan kualitas layanan ada beberapa inovasi DPMPTSP Provinsi Riau dalam bentuk Sistem IT yaitu (a) Rekomendasi Penelitian Onlie (RPO) yang sudah terintegrasi pada Sistem Informasi Manajemen Pelayanan (SIMPEL), (b) fitur Tanda Tangan Elektronik (TTE) yang telah memperoleh sertifikasi elektronik dari Badan dan Sandi Negara (BBSN) c.q. Balai Sertifikasi Elektronik (BsrE).

Seiring dengan kemajuan teknologi saat ini, DPMPTSP Provinsi Riau menghadirkan inovasi terbaru yakni, sistem perizinan berusaha terpadu elektronik (online single submission). Sistem ini telah diatur berdasarkan Peraturan Pemerintah Nomor 24 Tahun 2018 tentang Sistem Perizinan Berusaha Terintegrasi secara elektronik (online single Submission), dengan ini DPMPTSP Provinsi Riau melayani pelaku usaha yang membutuhkan informasi, bantuan dan konsultasi, antara lain:

1. Membantu menjelaskan permohonan perizinan berusaha yang tidak diatur dalam PP no. 24/2018, yang dilayani melalui DPMPTSP Provinsi Riau;

2. Membantu menjelaskan mengenai prosedur permohonan perizinan berusaha melalui sistem OSS; dan

3. Membantu memfasilitasi layanan informasi dan layanan berbantuan OSS.

Sistem ini berbasis android untuk pelayanan perizinan dan non perizinan di Provinsi Riau untuk meningkatkan lagi kualitas pelayanan publik. Dengan adanya inovasi diatas, DPMPTSP Provinsi Riau memberikan kemudahan kepada palaku usaha dan mahasiswa/i yang ingin mengurus surat rekomendasi penelitian secara online, namun inovasi ini belum banya dikenal masyarakat.

Keberhasilan organisasi birokasi dalam pelayanan publik telah diperoleh oleh Pemerintah Provinsi (Pemprov) Riau mendapatkan penghargaan dari Pemerintah Pusat, selama kepemimpinan Arsyadjuliandi Rachman.Kali ini Riau menjadi nomor dua terbaik se-Indonesia setelah DKI Jakarta.Kali ini Riau Mendapatkan melalui Dinas Penanaman Modal dan Pelayanan Terpadu Satu Pintu (DPM-PTSP) menerima penghargaan dari Menteri Pendayagunaan Aparatur Negara dan Reformasi Birokrasi (Manpan-RB) Tahun 2018. DPM-PTSP Riau mendapat penghargaan sebagai Role Model Penyelenggaraan Pelayanan Publik Kategori A.

Evaluasi dan pemberian penghargaan ini bertujuan untuk memotivasi dan mengapresiasi Kementerian, Lembaga, dan Pemerintah Daerah yang dijadikan Role Model untuk dapat menerapkan kebijakan Undang-Undang Nomor 25 Tahun 2009 tentang Pelayanan Publik secara baik dan benar serta mendorong Kementerian, Lembaga, dan Pemerintah Daerah Role Model untuk berkompetisi untuk mewujudkan pelayanan prima.

Setelah memperoleh penghargaan tersebut DPMPTSP Provinsi Riau menajadi tuan rumah Rapat Koordinasi Nasional (Rakornas) Sosialisasi Kebijakan Penyelenggaraan Pelayanan Terpadu Satu Pintu (PTSP) Daerah se-Indonesia dalam rangka mencontoh kinerja DPMPTSP Provinsi Riau yang meraih predikat terbaik dengan nilai A dari Kementerian Pendayagunaan Aparatur Negara dan Reformasi Birokrasi (Kemenpan RB) Republik Indonesia. keberhasilan ini tidak terlepas dari peran Kepala DPMPTSP dalam menjalankan Permendagri Nomor 138 Tahun 2017 tentang Penyelenggaraan Pelayanan Terpadu Satu Pintu Daerah. Pada tahun-tahun sebelumnya DPMPTSP Provinsi Riau telah memperoleh beberapa penghargaan, diantaranya: 
Tabel 1. Penghargaan DPMPTSP Provinsi Riau

\begin{tabular}{|c|c|c|}
\hline NO & Tahun & Penghargaan \\
\hline 1 & 2012 & Citra Pelayanan Prima dari MenpanRB RI \\
\hline 2 & 2012 & Investment Awarad dari BKPM RI \\
\hline 3 & 2014 & Predikat Kepatuhan Standar Pelayanan Publik dari \\
\hline 4 & 2016 & Obdusman RI \\
\hline & & Predikat Kepatuhan Tinggi Standar Pelayanan \\
\hline 5 & 2018 & $\begin{array}{l}\text { Publik dari Obdusman RI } \\
\text { Role Model Penyelenggaraan Pelayanan Publik }\end{array}$ \\
\hline 6 & 2018 & "Sangat baik". Dari Menpan RB \\
\hline 7 & 2019 & $\begin{array}{l}\text { Unit Penyelenggara Pelayanan Publik Ktegori } \\
\text { "Pelayanan Prima" Dari Menpan RB } \\
\text { Role Model Penyelenggaraan Pelayanan Publik } \\
\text { Kategori "Pelayanan Prima". Dari Menpan RB }\end{array}$ \\
\hline
\end{tabular}

Dari hal diatas maka penelis merumuskan permasalahan dalam penelitian ini yaitu"bagaimana pelaksanaan inovasi pelayanan publik yang menjadi best practice Pada Dinas Penanaman Modal dan Pelayanan Terpadu Satu Pintu (DPMPTSP) Kota Pekanbaru? dan faktor apa saja yang mendukung proses pelaksanaan inovasi pelayanan di DPMPTSP Provinsi Riau.

Proses lahirnya suatu inovasi bisa didorong oleh bermacam situasi. Secara umum inovasi dalam layanan publik ini bisa lahir dalam bentuk inisiatif seperti :

1. Kemitraan dalam penyampaian layanan publik, baik antara pemerintah dan pemerintah, sektor swata dengan pemerintah, CBO-NGO dengan pemerintah.

2. Penggunaan teknologi informasi untuk komunikasi dalam pelayanan publik.

3. Pengadaan atau pembentukan lembaga layanan yang secara jelas meningkatkan efektiftas layanan (kesehatan, pendidikan, hukum, atau keamanan masyarakat).

4. Peningkatan pengayaan peran atas sistem internal pemerintahan yang sebelumnya sudah ada di dalam masyarakat.

Muttaqin dalam (Deddy Mulyadi:2018) bahwa birokrasi yanng dapat melakukan inovasi dalam pelayanan publik, apabila beberapa faktor berikut diperhatikan dalam upaya membangun birokrasi pemerintahan. Faktor-faktor tersebut berinteraksi satu dengan yang lain dan terintegrasi dalam meciptakan birokrasi pemerintahan yang inovatif. Faktor-faktor tersebut berada pada tataran individu aparatur birokrasi pemerintahan, di bawah.

Menurut Asian Development Bank inovasi dalam (Marten Prasetyo Junior,2016 : 6) adalah Sesuatu yang baru, dapat di implementasikan, dan memliki dampak yang menguntungkan. Inovasi bukan sebuah kejadian ataupun aktivitas; ini adalah konsep, proses, penerapan, dan kapabilitas yang menentukan kesuksesan organisasi. Inovasi dapat membantu sektor publik untuk membuat nilai untuk masyarakat.

Berdasarkan definisi diatas, secara khusus inovasi di dalam lembaga publik bisa didefinisikan sebagai penerapan (upaya membawa) ide-ide baru dalam implementasi, dicirikan oleh adanya perubahan langkah yang cukup besar, berlangsung cukup lama dan berskala cukup umum sehingga dalam proses implementasinya berdampak cukup besar terhadap perubahan organisasi dan tata hubungan organisasi. Ditinjau secara lebih khusus, pengertian inovasi didalam pelayanan publik bisa diartikan sebagai presentasi dalam meraih, meningkatkan dan memperbaiki efektifitas, efisiensi dan akuntabilitas pelayanan publik yang dihasilkan oleh inisiatif pendekatan metodelogi, dan atau alat baru dalam pelayanan masyarakat. 
Jadi dapat disimpulkan bahwa inovasi dalam pelayanan publik yaitu suatu gagasan baru atau modifikasi ide yang sudah ada yang dihasilkan oleh inisiatif-inisiatif pengetahuan dalam rangka menciptakan sistem pelayanan pada masyarakat yang efektif dan efisien.

\section{METODE}

Menurut Sugiono (2012:11) jenis penelitian yang digunakan dalam penelitian ini adalah penelitian deskriptif kualitatif yaitu penelitian yang digunakan untuk mengetahui variabel mandiri, baik satu variabel atau lebih (independen) tanpa membuat perbandingan atau menghubungan antara variabel satu dengan variabel yang lainnya.Penelitian ini dilakukan di Dinas Penanaman Modal dan Pelayanan Terpadu Satu Pintu(DPMPTSP) Provinsi Riau.Pemilihan lokasi penelitian ini berdasarkan fenomena atau masalah yang positif bahwa DPMPTSP Provinsi Riau memperoleh penghargaan pelayanan publik terbaik se-nasioanal dari Kementerian Pendayagunaan Aparatur Sipil Negara dan Reformasi Birokrasi pada Tahun 2018.Teknik pengumpulan data yang di gunakan melalui observasi, wawancara dan dokumentasi.Adapun informan penelitian ini: Kepala DPMPTSP Provinsi Riau, Kepala Bidang DPMPTSP Provinsi Riau, Pegawai DPMPTSP Provinsi Riau, dan Masyarakat.Langkah-langkah analisis data pada penelitian kualitatif menurut Miles and Huberman dalam (Sugiyono 2012:337) adalah reduksi data, penyajiandata dan verifikasi data.

\section{HASIL DANPEMBAHASAN}

\subsection{Pelaksanaan Inovasi Dinas Penanaman Modal dan Pelayanan Terpadu Satu Pintu (DPMPTSP) Provinsi Riau}

Inovasi pelayanan publik adalah suatu ide-ide atau gagasan mengenai pelayanan publik yang sifatnya baru maupun modifikasi yang sudah ada, yang mana sesuai peraturan yang berlaku tentang pedoman inovasi pelayanan publik dan kompetisi pelayanan publik bahwasannya setiap instansi diharuskan untuk membuat minimal satu inovasi satu instansi. Adapun bentuk inovasi pelayanan publik yang di buat Dinas Penanaman Modal dan Pelayanan Terpadu Satu Pintu (DPMPTSP) Provinsi Riau dalam terlaksana nya inovasi yang baik yaitu Inovasi dalam bentuk Sistem IT yakni:

1. Sistem Perizinan berusaha terpadu elektronik/OSS (One Single Submission)

2. Rekomendasi Penelitian Online (RPO)

3. Fitur TTE (Tanda Tangan Elektronik)

Melalui fitur tersebut pemohon dapat mengetahui informasi detail persyaratan, informasi prosedur berdasarkan SOP, informasi mekanisme perizinan dan non perizinan, e-antrian secara elektronik, pengaduan secara online secara mudah serta cepat. Sistem OSS (One Single Submission) juga dapat di unduh di aplikasi android Playstore (Mobile Perizinan Riau 2019) bagi pemohon (pengusaha) yang ingin mendapatkan informasi detail dengan fitur tracking untuk mengetahui status permohonan secara realtime.

Bagi pelaku usaha yang ingin membuat surat izin usaha secara online dapat melakukan pedaftaran melalui fitur OSS (One Single Submission) sistem perizinan berusaha terpadu elektronik, selanjutnya pemohon akan mendapatkan NIB (nomor izin berusaha), setalah itu mengajukan persyaratan izin usaha yang sudah tertera, kemudian petugas DPMPTSP Provinsi Riau akan memproses data yang masuk sesegera mungkin dan pemohon dapat output berupa surat legal izin usaha yang sudah terintegrasi tanda tangan elektronik (TTE). 
PeluncuranAplikasi Rekomendasi Penelitian Online (RPO), maka Pemohon tidak harus datang ke kantor DPMPTSP dan cukup mengakses secara online pada aplikasi tersebut, kemudian mendapatkan output berupa surat rekomendasi penelitian yang bertandatangan dan tersertifikasi sah secara elektronik. Surat Rekomendasi Penelitian selanjutnya dapat dicetak secara mandiri oleh Pemohon, sehingga pemohon akan menghemat waktu dan biaya serta meminimalisir resiko atas pengurusan Rekomendasi Penelitian. Selain itu pihak univesrsitas, sekolah tinggi maupun akademi akan mendapatkan data base penelitian yang akan dilaksanakan oleh mahasiswa / mahasiswi.

Birokrasi yang dapat melakukan inovasi dalam pelayanan publik, apabila beberapa faktor berikut diperhatikan dalam upaya membangun birokrasi pemerintahan.Faktor-faktor tersebut berada pada tataran individu aparatur birokrasi pemerintahan, kelembagaan, sistem, dan masyarakat.

\subsection{Tataran Individu Aparatur}

Berdasarkan hasil kutipan wawancara yang dilakukan kepada Pegawai Dinas Penanaman Modal dan Pelayanan Terpadu Satu Pintu (DPMPTSP) Provinsi Riau bahwa Aparatur DPMPTSP Provinsi Riau sudah mengetahui dan paham terhadap tugas dan fungsi dari organisasi maupun tugas masingmasing ASN. Disini pengetahuan sangat penting bagi aparatur agar mudah dalam menjalankan tugas sebagai pemberi pelayanan publik dan berlaku juga "the right man, in the right place" aparatur ditempatkan sesuai dengan tingkat pengetahuan dan kemampuan yang dimilikinya agar memudahkan dalam menyelesaikan segala masalah. Meskipun tidak semua pegawai mengikuti pelatihan/pengembangan, DPMPTSP Provinsi Riau telah melakukan yang terbaik dalam meningkatkan kualitas aparaturnya.

\subsection{Tataran Kelembagaan}

Indikator dari tataran kelembagaan merupakan unsur yang penting dalam sebuah lembaga/organisasi pemerintah dalam menyelenggarakan pelayanan publik ialah kepemimpinan, sumber daya, pengambilan keputusan dan sistem informasi manajemen.

Berdasarkan hasil wawancara bahwa gaya kepemimpinan yang diterapkan oleh Pimpinan Dinas Penanaman Modal dan Pelayanan Terpadu Satu Pintu (DPMPTSP) Provinsi Riau merupakan gaya kepemimpinan yang mengacu pada hubungan. Di sini seorang pemimpin selalu mengadakan hubungan dengan yang dipimpinnya.Setiap ada permasalahan selalu mengikutsertakan bawahan sebagai suatu tim yang utuh. Tipe kepemimpinan demokrasi yang di DPMPTSP Provinsi Riau sangat ideal diterapkan, tipe demokrasi mengedepankan sistem kerjasama sehingga terdapat koordinasi pekerjaan dari semua bawahan dan mau mendengarkan saran dan kritikan yang sifatnya membangun.

Beberapa Pegawai Dinas Penanaman Modal dan Pelayanan Terpadu Satu Pintu (DPMPTSP) Provinsi Riau, bahwa pimpinan DPMPTSP Provinsi Riau memiliki kepribadian dan kemampuan yang dapat memberikan pandangan positif terhadap bawahan nya serta dapat menciptakan lingkungan kerja yang nyaman dan kondusif.

Sumber daya yang dimiliki Dinas Penanaman Modal dan Pelayanan Terpadu Satu Pintu (DPMPTSP) Provinsi Riau telah sebanding dengan beban kerja yang ada, DPMPTSP Provinsi Riau telah mengeluarkan kurang lebih 13.000 izin tiap tahunnya dan di dukung dengan sumber daya aparatur yang berkompeten dan profesional yang bisa di lihat dari tabel di bawah ini: 


\section{Gambar 1 Kompetensi Aparatur DPMPTSP Provinsi Riau}

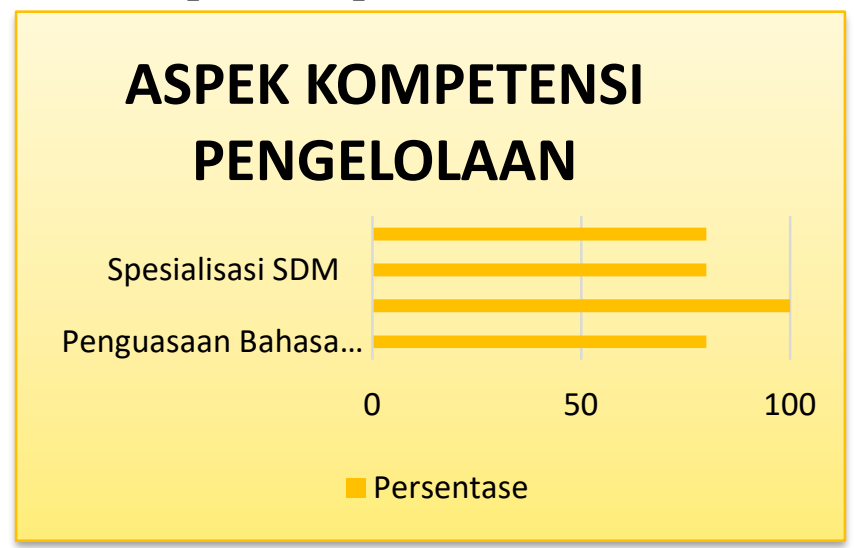

Sumber:Sumber :LkjIP 2018 Dinas Penanaman Modal dan Pelayanan Terpadu Satu Pintu (DPMPTSP) Provinsi Riau

Berdasarkan kutipan wawancara yang dilakukan kepada Sekretaris dan Kepala Seksi Kebijakan dan Penyuluhan Layanan Dinas Penanaman Modal dan Pelayanan Terpadu Satu Pintu (DPMPTSP) Provinsi Riau, bahwa sistem informasi manajemen sudah lengkap dan terintegrasi dengan baik melalui website resmi dpmptspriau.go.id yang menyajikan data dan informasi terkait profil organisasi, informasi (berita, agenda,dan galeri), jenis dan persyaratan perizinan, standar pelayanan, mekanisme perizinan, perizinan online, indeks kepuasan masyarakat (IKM), program dan kegiatan (laporan realisasi keuangan dan laporan realisasi anggaran) yang sudah dipublikasikan secara transparan.

DPMPTSP Provinsi Riau memiliki tata kelola organisasi yang baik, dalam manajemen pelayanan sudah tersedia aplikasi pengolahan data perizinan secara komputerisasi seperti Sistem Informasi Manajemen Pelayanan (SIMPEL), dan aplikasi online yang dapat di akses melalui media internet lainnya.Sistem informasi manajemen DPMPTSP Provinsi Riau telah memberikan kemudahan masyarakat dalam memberikan pelayanan meskipun masih ada beberapa izin usaha yang belum terintegrasi dengan tanda tangan elektronik.

\subsection{Tataran Sistem}

Berdasarkan kutipan wawancara diatas bahwa Dinas Penanaman Modal dan Pelayanan Terpadu Satu pintu (DPMPTSP) Provinsi Riau telah melaksanakan aturan yang berlaku dengan baik dibuktikan dengan diperolehnya beberapa penghargaan kepatuhan tinggi standar pelayanan publik dari Obdusman RI yang menunjukkan bahwa DPMPTSP Provinsi Riau mampu memberikan pelayanan kepada masyarakat sesuai dengan standar pelayanan yang diamanatkan oleh UU 25 tahun 2009 tentang Pelayanan Publik.

\subsection{Tataran Masyarakat}

Indikator dari tataran masyarakat ialah pengetahuan, kontrol, kerjasama, dan prokatif. Masyarakat merupakan penerima layanan dari organisasi pemerintah yang menyelenggarakan pelayanan publik dan berhak mendapatkan pelayanan yang prima. Berdasarkan kutipan wawancara yang dilakukan kepada Sekretaris dan Kepala Seksi Kebijakan dan Penyuluhan Layanan Dinas Penanaman Modal dan Pelayanan Terpadu Satu Pintu (DPMPTSP) Provinsi Riau, bahwa DPMPTSP Provinsi Riau telah melakukan sosialiasi kepada masyarakat dalam bentuk seminar, diskusi bahkan membuat grup diskusi bersama pihak kampus terkait inovasi rekomendasi penelitian/riset online. Bentuk kontrol masyarakat terhadap pelayanan publik dengan diberikan nya 
kertas angket kepada setiap pengunjung ke DPMPTSP Provinsi Riau, dari angket tersebut di rekap perbulan dan $\mathrm{h}$ asil nya menunjukkan sangat baik.

Tabel 2

Indeks Kepuasan Masyarakat Januari-Juni 2019

Berkenaan dengan hal tersebut diatas, berikut disampaikan Nilai Survei Kepuasan Masyarakat (SKM) pada bulan Juni 2019 tersebut :

\begin{tabular}{llccl}
\hline No. & Bulan & Jumlah Responden & Nilai & Mutu Pelayanan \\
\hline \hline 1. & Januari & 314 & 98.362 & Sangat Baik \\
\hline 2. & Februari & 297 & 99.255 & Sangat Baik \\
\hline 3. & Maret & 349 & 99.622 & Sangat Baik \\
\hline 4. & April & 300 & 99.299 & Sangat Baik \\
\hline 5. & Mei & 315 & 99.319 & Sangat Baik \\
\hline 6. & Juni & 225 & 99.567 & Sangat Baik \\
\hline
\end{tabular}

Rekapitulasi dan perbandingan pengolahan Survei Kepuasan Masyarakat (SKM) dan Per Unsur Pelayanan yang diberikan Dinas Penanaman Modal dan Pelayanan Terpadu Satu Pintu (DPMPTSP) Provinsi Riau pada bulan Juni 2019 :

\begin{tabular}{clc}
\hline No. Unsur & \multicolumn{1}{c}{ Uraian Unsur } & Mutu Pelayanan \\
\hline \hline 1. & Kejelasan Kesesuaian Persyaratan & 3.977 \\
\hline 2. & Prosedur Pelayanan & 3.960 \\
\hline 3. & Kepastian Jadwal Pelayanan & 3.986 \\
\hline 4. & Kepastian/Biaya/Tarif Yang Dibayarkan & 4 \\
\hline 5. & Kepuasan Pelayanan Perizinan & 4 \\
\hline 6. & Kemampuan Petugas Pelayanan & 3.986 \\
\hline 7. & Kedisiplinan,Kesopanan dan Keramahan Petugas & 4 \\
\hline 8. & Pelaksanaan Maklumat Pelayanan & 4 \\
\hline 9. & Program Penanganan Pengaduan & 3.968 \\
\hline
\end{tabular}

Sumber : Dinas Penanaman Modal dan Pelayanan Terpadu Satu Pintu (DPMPTSP) Provinsi Riau

Peneliti juga melakukan wawancara dengan masyarakat yang sedang mengurus Surat Izin Penelitian di Dinas Penanaman Modal dan Pelayanan Terpadu Satu Pintu (DPMPTSP) Provinsi Riau yaitu Desi Wulandari (Mahasiswi Fisip UNRI) terkait pengetahuan nya terhadap inovasi Berdasarkan hasil wawancara terhadap masyarakat yang berkunjung ke Dinas Penanaman Modal dan Pelayanan Terpadu Satu Pintu (DPMPTSP) Provinsi Riau bahwa beberapa masyarakat terkhususnya mahasiswa sebagian sudah mengetahui dan masih ada yang belum mengetahui adanya inovasi di DPMPTSP Provinsi Riau.

\section{Faktor Pendukung Inovasi DPMPTSP Provinsi Riau}

Berdasarkan hasil wawancara dan observasi faktor pendukung inovasi Dinas Penanaman Modal dan Pelayanan Terpadu Satu Pintu dalam terwujudnya inovasi yang baik yaitu:

\section{Sumber Daya Manusia}

Sumber daya manusia merupakan salah satu unsur penting dalam dalam menggerakkan sebuah organisasi karena sumber daya manusia memegang yang berkualitas mempunyai peranan penting dalam keberhasilan sebuah organisasi. Berdasarkan kutipan wawancara diatas dapat diketahui bahwa DPMPTSP Provinsi Riau memiliki manajemen sumber daya manusia 
yang baik agar terwujudnya sumber daya manusia yang berkualitas dan berkarakter. sumber daya manusia yang berkualitas dapat dilihat dari tingkat pendidikan yang semakin meningkat.

\section{Komitmen Pimpinan}

Berdasarkan kutipan wawancara diatas bahwa komitmen pimpinan DPMPTSP Provinsi Riau ialah menjalankan peraturan Peraturan Menpan-RB No 24 Tahun 2014 tentang pedoman pengelolaan pelayanan publik dengan baik bersama kepala daerah dan aparatur dalam mewujudkan pelayanan prima kepada masyarakat. Komitmen pimpinan merupakan sebuah kunci untuk perbaikan kualitas pelayanan publik dengan menciptakan inovasi pelayanan publik. Karena keaktifan pimpinan dan kerjasama aparatur DPMPTSP Provinsi Riau telah memperoleh banyak penghargaan dalam kurun waktu 5 tahun ini.

\section{Sarana dan Prasarana}

Berdasarkan hasil wawancara dan observasi DPMPTSP Provinsi Riau memiliki fasilitas yang sangat lengkap seperti ruang lansia dan disabilitas, ruang konsultasi, ruang laktasi, ruang data center, ruang back office, pomdok ceria, dan ruang bermain anak. Selain ruang pelayanan, juga tersedia ruang pengaduan yang nyaman sesuai SOP dan mekanisme yang telah ditetapkan baik secara langsung maupun mobile, ruang klinik LKPM juga disediakan untuk mempermudah investor dalam menyampaikan kegiatan penanaman modal, konsultasi serta membahas permasalahan investasi untuk menciptakan iklim investasi yang kondusif.

\section{Integritas}

Berdasarkan hasil wawancara dan observasi bahwa aparatur di DPMPTSP Provinsi Riau bukan hanya profesional tetapi juga berintegritas dalam memberikan pelayanan publik.ASN memberikan pelayanan kepada masyarakat sesuai aturan dan prosedur yang berlaku, nilai etika pelayanan 3SC (senyum ceria, santun ceria, sapa ceria) dan Motto Pelayanan CERIA (cepat melayani, efisien dalam bekerja, responsif menyikapi, integritas dan akuntabel) dan di dukung dengan fasilitas yang lengkap.Dan peneliti juga melihat bahwa setiap aparatur menggunakan pin tag yang bertuliskan menolak grativikasi sebagai bentuk budaya ASN Dinas Penanaman Modal dan Pelayanan Terpadu Satu Pintu (DPMPTSP) Provinsi Riau.Integritas DPMPTSP Provinsi Riau dalam bentuk komitmen antara pimpinan dan aparatur dalam memberikan pelayanan prima kepada masyarakat.

\section{Anggaran}

Berdasarkan hasil wawancara dan observasi peneliti bahwa anggaran merupakan hal terpenting. Sejauh ini anggaran berjalan baik untuk pelaksanaan inovasi yang di laksanakan Dinas Penanaman Modal dan Pelayanan Terpadu Satu Pintu (DPMPTSP) Provinsi Riau yaitu Inovasi Sistem IT yakni Inovasi Pelayanan Perizinan Terintegrasi Secara Elektronik (Online Single Submission/OSS) dan rekomendasi penelitian Online (RPO) yang dilakukan secara elektronik dan online. Namun brosur ristet online dan lainnya sudah mulai habis berdasarkan observasi peneliti saat berkunjung, mengingat brosur merupakan satu hal yang penting dalam sosialisasi secara tidak langsung agar masyarakat mengetahui keberadaan inovasi dan mekanisme inovasi pelayanan. 


\section{KESIMPULAN}

Dari penelitian mengenai keberhasilan inovasi Dinas Penanaman Modal dan Pelayanan Terpadu Satu Pintu (DPMPTSP) Provinsi Riau peneliti mengambil kesimpulan bahwa DPMPTSP Provinsi Riau dalam pelaksanaan inovasi terhadap upaya pelaksanaan percepatan dan peningkatan pelayanan perizinan berusaha terintegras secara elekttonik di Provinsi Riau kepada masyarakat sudah maksimal dan semakin meningkat karena inovasi pelayanan yang dimiliki kurang lebih 14 inovasi pelayanan publik secara elektronik/online dan manual. Berdasarkan hasil penelitian yaitu:

a. Inovasi Pelayanan Perizinan Terintegrasi Secara Elektronik (Online Single Submission/OSS)

b. Inovasi Rekomendasi Penelitian Online

c. Tanda Tangan Elektroni (TTE)

Pelaksanaan dari ketiga inovasi yang dilaksanakan oleh Dinas Penanaman Modal dan Pelayanan Terpadu Satu Pintu (DPMPTSP) Provinsi Riau secara elektonik dengan motto pelayanan CERIA (cepat,efisien, responsif, integritas, dan akuntabel) sudah dikatakan berhasil dan dapat diterima oleh masyarakat sebagai pengguna layanan. Perubahan yang terjadi dari segi dampak nya yaitu peningkatan dari jumlah realisasi investasi Provinsi Riau selama 3 tahun cukup signifikan dan peningkatan indeks kepuasan masyarakat (IKM).

Faktor pedukung inovasi di Dinas Penanaman Modal dan Pelayanan Terpadu Satu Pintu (DPMPTSP) Provinsi Riau dalam upaya pelaksanaan percepatan dan peningkatan pelayanan perizinan berusaha terintegras secara elekttonik yaitu sumber daya manusia yang memumpuni, komitmen pimpinan dalam menjalankan Peraturan Menpan-RB No 24 Tahun 2014 tentang pedoman pengelolaan pelayanan publik dengan baik, sarana dan prasarana yang lengkap dan memadai, integritas aparatur dalam memberikan pelayanan publik yang prima dan anggaran yang memadai dalam menjalankan inovasi pelayanan publik dan terealisasikan secara maksimal.

Keberhasilan DPMPTSP Provinsi Riau dalam memperoleh penghargaan pelayanan publik dapat dilihat dari faktor kepemimpinan yang kuat, berkarakter, bukan hanya cerdas tapi juga mampu menjalin hubungan yang harmonis dengan aparatur sehingga menciptakan lingkungan kerja yang inovatif dan nyaman. selain itu partisipasi masyarakat yang terlibat dalam keberhasilan pembangunan, ditunjukkan dengan keaktifan masyarakat Provinsi Riau dalam penggunaan layanan inovasi dan hasil indeks kepuasan masyarakat yang sangat baik. Kemudian sumber daya manusia yang dimiliki DPMPTSP Provinsi Riau yang profesional, berkompeten dan berintergrasi. Maka DPMPTSP Provinsi Riau sudah bisa dijadikan sebagai role model pelayanan publik yang baik dalam daerah maupun skala nasional.

\section{SARAN}

Berdasarkan kesimpulan mengenai keberhasilan inovasi pelayanan yang dilakukan oleh Dinas Penanaman Modal Dan Pelayanan Terpadu Satu Pintu (DPMPTSP) Provinsi Riau yang dikemukan diatas, maka diajukan saran sebagai bahan pertimbangan dalam rangka memperbaiki peranan Dinas Penanaman Modal Dan Pelayanan Terpadu Satu Pintu (DPMPTSP) Provinsi Riau, sebagai berikut:

1. Sebaiknya Dinas Penanaman Modal dan Pelayanan Terpadu Satu Pintu (DPMPTSP) Provinsi Riau untuk Sistem Informasi Manajemen terkait fitur Sipenasakti agar sistemnya di perbarui dan ditambah jumlah pilihannya dikarenakan banyak peneliti dari lembaga pendidikan yang lainnya agar Inovasi Rekomendasi Penelitian Online (RPO) juga dapat dirasakan secara merata.

2. Sebaiknya Dinas Penanaman Modal dan Pelayanan Terpadu Satu Pintu (DPMPTSP) Provinsi Riau setelah memperbarui Sistem terkait SiPenaSakti, maka perlu dilakukan sosialisasi kembali ke pihak akademik 


\section{DAFTAR PUSTAKA}

[1] Dwiyanto, Agus. 2011. Mengembalikan kepercayaan public melalui reformasi birokrasi. Jakarta: Gramedia Pustaka Utama

[2] Emzir.2012. Metode Penelitian Kualitatif Analisis Data. Jakarta: Rajawali Pers.

[3] Hayat. 2017. Manajemen Pelayanan Publik. Jakarta: Rajawali Pers.

[4] Marten Prasetyo Junior. 2016. Jurnal Inovasi Pelayanan Publlik. Jurusan Ilmu Pemerintahan Fakultas Ilmu Sosial dan Ilmu Politik. Universitas Diponegor Semarang

[5] Mirnasari, Rina Mei. 2013. Inovasi Pelayanan Publik UPTD Terminal Purabaya Bungurasih. Universitas Airlangga. Volume 1.

[6] Mulyadi, Deddy. 2018. Administrasi publik untuk pelayanan publik. Jakarta: Alfabeta Bandung

[7] Muluk, Khairul.2008. knowledge Manajemen: Kunci sukses inovasi pemerintah daerah. Malang: Bayu Media

[8] Singarimbun, Masri. Sofian Effendi. 2006. Metode penelitian survai. Jakarta Barat: Pustaka LP3ES

[9] Sinambela, Lijan Poltak. 2011. Reformasi Pelayanan Publik : Teori Kebijakan Dan Implementasi. Jakarta: Bumi Aksara.

[10] Sugiyono. 2012. Metode penelitian kuantitatif kualitatif dan $R \& D$. Bandung: Alfabeta

[11] Suwarno, Yogi. 2008. Inovasi di Sektor Publik.e-book, Jakarta: STIA-LAN Press

[12] Undang-Undang Nomor 25 Tahun 2009 tentang Pelayanan Publik

[13] Permen RB RI Nomor 30 Tahun 2014 tentang pedoman inovasi pelayan publik 